sufficient interest in science. We may hope that in the yearly volumes of a periodical like NATURE, the general reader will find everything brought down to the latest date, with a sufficiently clear account of all important discoveries. There is needed, however, a sort of "bird'seve view" book of the year's work, in which a great deal that emerges every week and is of little permanent importance, may be left out, and really considerable discoveries alone given. It is necessary, besides, that the narrative of these discoveries should not be written from the point of view of the man of science, who knows at once where to place them in relation to his previous knowledge. A brief account must be added of that part of what has been accepted or known which the new-acquisition illustrates, supplements, or contradicts.

Thus in the description of Wüllner's interesting investigations, confirming those of Frankland and Lockyer as to the alterations which take place in gas spectra when the pressure of the gas is altered, it is necessary to give some account of the previously accepted doctrine of Plücker's "spectra of the first order," and "spectra of the second order." Again, it is useless to describe discoveries relating to circular polarisation without recalling to the general reader the meaning of the term.

We need not attempt in this place to give any account of the new discoveries which are explained in the Fahrbuch. It is a closely-printed volume of 416 pages, with 43 illustrations, and its execution appears to us as excellent as its plan. There is a full account of the acquisitions in solar and stellar physics, which have made the year I 868 memorable in science. In molecular physics we have Graham's discussion of the absorption of hydrogen by palladium. In acoustics we have a careful compendium of Regnault's recent laborious and excellent work on the velocity of sound propagation and of the less gigantic experiments by Kundt, which have since been followed out by Schneebeli and Seebeck with promise of bringing us to results more interesting and important from a theoretical point of view than those of Regnault. In heat there is a full account of the investigations, especially with regard to dark heat by Magnus and Dessains. We have all the modifications and improvements in "influence machines," like that of Holtz, which have been realised in the year. For domestic readers there are 25 pages on the sewing machine-single stitch, double stitch, and lock stitch, and 7 more on the knitting machine. Finally, there is a mass of detail, much of it extremely interesting, on the latest chemical discoveries, appropriately introduced by an account of Bunsen's method of washing and filtering precipitates under the pressure of a column of water.

W. J.

Mohr's Titrirmethode,-Lehrbuch der Chemisch-Analytischen Titrirmethode. Von Dr. Friedrich Mohr. Third and improved edition. Part I. (Brunswick: i 870.$)$

WE are glad to see that Dr. Mohr's well-known work on volumetric analysis has reached a third edition, and that the author, who well deserves to be called the fosterparent of this branch of chemistry, has taken advantage of the opportunity to recast it entirely. We cannot do better than state his own account of its contents :-

"The work proffers; in the first place, an introduction to the manipulation and use of instrumental appliances, of which the best forms are completely described. Then follows Alkalimetry, under which are comprised all analyses that terminate with the saturation of acids and alkalies. The determination of potash, soda, ammonia, earths, and free acids generally is here described.

"The third section embraces analyses by reduction and oxidation, and especially their subdivision, according as permanganate, dichromate, or iodine solution is added in the final stage. It will be found to contain the determination of chlorine, iodine, bromine, chromic acid, all peroxides, and generally all substances which evolve or combine with oxygen, chlorine, cyanoger, \&c. The next section includes analyses by precipitation, the estimation of silver, chlorine, cyanogen, copper, lead, \&c.-where a precipitation begins or ends the process.

"The conclusion of the work" (which has not yet reached us) "is the practical part, which teaches the application of individual methods to the entire course of an analysis. Complete methods are stated for the analysis of alkalies, salt-cake, mineral waters, soils, guanos, and the. ores of copper, zinc, and iron."

Those of our readers who are acquainted with the previous edition will perceive, from the above account of the contents of the present one, that Dr. Mohr has very much extended his original plan. Accordingly the new Lehrbuch contains six additional sheets, and thirteen fresh woodcuts. We need hardly say that the author has executed his work with the detailed care and enthusiasm which are known to characterise him ; and the numerous illustrations, for which Messrs. Vieweg are responsible, are as remarkable for sharpness and portraiture as those in most English manuals are deficient in these respects. We shall feel much interested in reading the conclusion of the book, which will supply a want long felt in certain departments of manufacture. For the sake of English experimenters who are not familiar with German, a translation of the entire work, adapted to the prevailing notation, would be very desirable.

\section{THE TRIAL OF THE PYX}

THE trial of the Pyx is the formal testing of the coin of the realm, to ensure its being of the requisite weight and fineness. The name is derived from the Pyx, or chest, in which the coins selected for the purpose are contained. The first trial of the Pyx took place in the ninth and tenth years of Edward I. And as the last observance of this ancient ceremony was held during the past week, a few brief notes may not be without interest.

The authority under which the trials were made varied considerably. First, the members of the King's Council, then the Barons of the Exchequer constituted the court, King James I. presiding at one trial. The court now consists of several tnembers of the Privy Council, under the presidency of the Lord High Chancellor and a jury selected from the Hon. Company of Goldsmiths.

Last week the high officers of the Mint assembled at the Treasury, and in their presence the Lord Chancellor charged the jury to examine the coin of the late Master of the Mint; Thomas Graham, F.R.S., and to ascertain whether it was within the latitude of "remedy" allowed by law:

This remedy amounts to $1 \mathrm{z}$ grains on each troy pòuth of gold coin, or to 0257 grain on each sovereign ; and 24 grains on each pound troy of silver coin. Portions cut from standard test-plates were handed to the jury who adjourned to Goldsmiths' Hall. They then opened the Pyx-chest and tested the coin by weight; having done this, a certain number of gold coins were melted into an ingot, which was then assayed; the same process being adopted with the silver coin. In the present instance the Pyx represented a coinage of 14 millions gold and I million of silver coin ; the verdict of the jury being, that the coin both as to weight and fineness was within the remedy allowed by law. The details, however, were most favourable to the late illustrious Master who has so lately passed away.

An adverse verdict would probably have been followed by no more serious penalty than the forfeiture of the Master's sureties, but it is interesting to note that in the reign of Henry $I$. the money was so debased as to call for the exemplary punishment of the "Moneyers," while in Anglo-Saxon times the chief officer or Reeve would have been punished by the loss of his hand should he fail to clear himself of the charge of producing false coinage. 